\title{
Aerosol-Based Delivery of Fibroblast Cells for Treatment of Lung Diseases
}

\author{
E. Kardia, BSc, N.M. Yusoff, MBBS, DCP, MMedSc, PhD, \\ Z. Zakaria, MBBS, DCP, ${ }^{2}$ and B. Yahaya, BSc, MSc, PhD ${ }^{1}$
}

\begin{abstract}
Background: Cell-based therapy has great potential to treat patients with lung diseases. The administration of cells into an injured lung is one method of repairing and replacing lost lung tissue. However, different types of delivery have been studied and compared, and none of the techniques resulted in engraftment of a high number of cells into the targeted organ. In this in vitro study, a novel method of cell delivery was introduced to investigate the possibility of delivering aerosolized skin-derived fibroblasts.

Methods: Skin-derived fibroblasts were trypsinized and resuspended in growth medium. A syringe filled with cells $\left(10^{5}\right.$ cells $\left./ \mathrm{mL}\right)$ was attached to MicroSprayer ${ }^{\circledR}$ Aerosolizer, a device that can modify a liquid into an aerosol. The tip of the MicroSprayer Aerosolizer was channeled into a T25 flask containing growth medium. Survivability following aerosolization was observed on a daily basis. HeLa cells were used for comparison. The same aerosolization and culture methods were used to treat HeLa cells.

Results: One day following aerosolization, skin-derived fibroblasts showed no sign of vacuolation due to cell stress. They attached to the surface of the flask, indicating that most of them survived aerosolization. The surviving cells were also able to proliferate rapidly, forming a confluent monolayer of cells at day 4 . In contrast, HeLa cells were unable to proliferate even after 21 days of culture.

Conclusions: This study provides the first evidence that cells can be aerosolized without the risk of low cell survivability and stress. The high survival rate of fibroblast cells following aerosolization illustrates the potential for delivering of such cells in future aerosol cell-based therapy to treat lung diseases.
\end{abstract}

Key words: aerosol delivery, cell-based therapy, MicroSprayer, skin-derived fibroblasts

\section{Introduction}

L UNG-RELATED DISEASES are the most commonly reported long-term illnesses in children and adults and include diseases such as chronic obstructive pulmonary disease, cystic fibrosis, and asthma. Cell-based therapy has great potential as an alternative modern treatment for patients with lung diseases. Cells can also serve as a vehicle to deliver a therapeutic gene for cell-based gene therapy to treat genetic airway diseases such as cystic fibrosis. ${ }^{(1)}$ However, low retention and engraftment of delivered cells are persistent obstacles in cell therapy applications. In addition, precise delivery and homing to the site of injury are essential and must be reassured for a successful therapy. Thus, accurate methods for delivering target cells to the targeted organ need to be carefully selected in order to improve cellular survivability and engraftment following administration.

In preclinical studies, the most common delivery routes of cells for cell therapy to the lung are intravenous, ${ }^{(2,3)}$ intrapulmonary, ${ }^{(4)}$ intratracheal, ${ }^{(1,5)}$ and intraoral. ${ }^{(6)}$ Via these routes, cells can be administered down into the airway or through the pulmonary arterial circulation. Crisanti et al. and Xisto et al., who compared different routes of cell delivery, reported that the intratracheal route appears to be an effective way to deliver cells into the lung. ${ }^{(7,8)}$ Direct application of the cells into the lung makes intratracheal administration a more reliable and efficient means of delivering cells within a short period of time, compared with the longer times needed for other delivery routes. ${ }^{(7,9)}$ This method also results in good

${ }^{1}$ Cluster for Regenerative Medicine, Advanced Medical \& Dental Institute (AMDI), Universiti Sains Malaysia, Pulau Pinang, Malaysia.

${ }^{2}$ Cancer Research Center, Institute for Medical Research (IMR), Kuala Lumpur, Malaysia. 

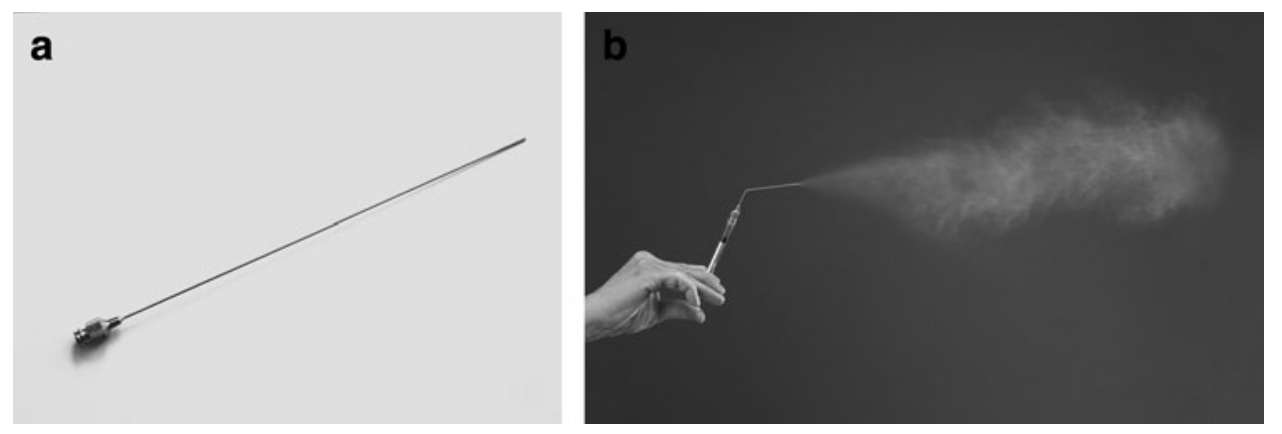

FIG. 1. (a) MicroSprayer Aerosolizer Model IA-1B is a device that can transform a liquid into an aerosol form. (b) The device produces a uniform and concentrated distribution of aerosolized liquid. (The photo is reproduced with permission of Penn-Century, Inc., Wyndmoor, PA.)

distribution of the cells in the lungs and reduces the risk of cell loss before reaching the lungs.

A new device-the MicroSprayer ${ }^{\circledR}$ Aerosolizer (PennCentury, Inc., Wyndmoor, PA)-has been invented to transform liquid into an aerosol form, which then can be applied via intratracheal administration (Fig. 1). This aerosolization method is usually used in pulmonary drug delivery by intratracheal inhalation ${ }^{(10)}$ and instillation. ${ }^{(11)}$ The formulation of aerosols has been designed to consist of small spherical droplets or particles that can penetrate into the airways or lung periphery, which then can lead to an optimal therapeutic effect for local and systemic therapeutic delivery. ${ }^{(12)}$

We used this device to study aerosol-based delivery of cells in a cell therapy application. The aims of this study were to investigate the survivability of skin-derived fibroblast cells following an aerosol type of delivery in vitro. This novel method has the potential for use as an aerosol-based delivery system for skin-derived fibroblast cells for the treatment of lung diseases.

\section{Materials and Methods}

\section{Isolation of skin-derived fibroblasts}

Skin-derived fibroblasts were collected from New Zealand white adult rabbits weighing $1-2 \mathrm{~kg}$. All experimental protocols were approved and the procedures were followed in accordance with the ethical standards of the Animal Ethics Committee of the Universiti Sains Malaysia (USM/Animal Ethics Approval/2010/63/258).

The rabbits were euthanized with pentobarbital $(1 \mathrm{~mL} / \mathrm{kg})$ administered intravenously. The skin was shaved with a clipper vacuum (Hazard Technology, Pasadena, MD) and cleaned with $70 \%$ ethanol. A piece of skin was excised from the lateral abdomen of the rabbit using a scalpel. The skin was then immediately placed in cold $1 \times$ phosphate-buffered saline (PBS) supplemented with 1\% antibiotic-antimycotic solution for transport to the laboratory. Unless specified otherwise, all reagents were obtained from Gibco-Life Technologies (Grand Island, NY).

\section{Skin-derived fibroblast culture}

The skin was dissected into pieces with a scalpel blade and submerged overnight in dispase solution made of $80 \mathrm{mg}$ of dispase II in $100 \mathrm{~mL}$ of PBS at $4^{\circ} \mathrm{C}$. After $24 \mathrm{hr}$, the skin was then incubated in $0.25 \%$ trypsin/EDTA for $10 \mathrm{~min}$ at $37^{\circ} \mathrm{C}$. Growth medium was added at the end of the trypsinization step. The collected cells were passed through a 70- $\mu \mathrm{m}$ mesh cell strainer (BD Falcon ${ }^{\mathrm{TM}}$, BD, Franklin Lakes, NJ) and then centrifuged at $1,500 \mathrm{rpm}$ for $5 \mathrm{~min}$. The cell pellet was resuspended in growth medium and cultured at $37^{\circ} \mathrm{C}$ and $5 \%$ $\mathrm{CO}_{2}$ in an incubator. The growth medium used was Dulbecco's modified Eagle's medium supplemented with $10 \%$ fetal bovine serum (FBS) and 1\% antibiotic-antimycotic solution.

\section{Aerosolized delivery of skin-derived fibroblasts}

Fibroblast cells were cultured until passage 3; they were trypsinized when they reached $80 \%$ confluence. FBS was added at the end of the trypsinization step, and afterwards the cells were centrifuged at 1,500 rpm for $5 \mathrm{~min}$ before being resuspended in growth medium. Concentration of the cells was determined using a hemocytometer; the result was $9.4 \times 10^{5}$ cells $/ \mathrm{mL}$. The sterile MicroSprayer Aerosolizer Model IA-1B containing $1 \mathrm{~mL}$ of skin-derived fibroblasts was gently inserted into a flask containing $4 \mathrm{~mL}$ of growth medium, and then the plunger was pushed with a firm constant pressure (700 psi). The survivability of the cells was observed under a microscope. The cells were cultured at $37^{\circ} \mathrm{C}$ and $5 \%$ $\mathrm{CO}_{2}$ for 4 days, and observations were made on a daily basis.

\section{Aerosolized delivery of HeLa cells}

HeLa cells were kindly donated by Dr. Azman Seeni (Toxicology Laboratory, Advanced Medical \& Dental Institute). The survivability of aerosolized HeLa cells was observed for 21 days.

\section{Results}

Most of the skin-derived fibroblast cells survived following aerosolization (Fig. 2). The morphology of the aerosolized skin-derived fibroblasts was similar to that of nonaerosolized cells (Fig. 3). On days 1 and 2, a few cells were found floating in the medium containing the aerosolized skin-derived fibroblast culture, indicating that they were dead. However, no vacuolated cells were observed among the surviving cells, and the cells were able to proliferate rapidly to become confluent within 4 days.

HeLa cells (with larger diameter) were also aerosolized for comparison with the skin-derived fibroblasts. Observations were made until day 21 (Fig. 4). A longer period of HeLa cell incubation gave more time for the cells to form a confluent layer of cells. However, due to the low number of cells surviving and a lot of cell debris present in the medium following aerosolization, the cells failed to proliferate after being cultured for 21 days. 

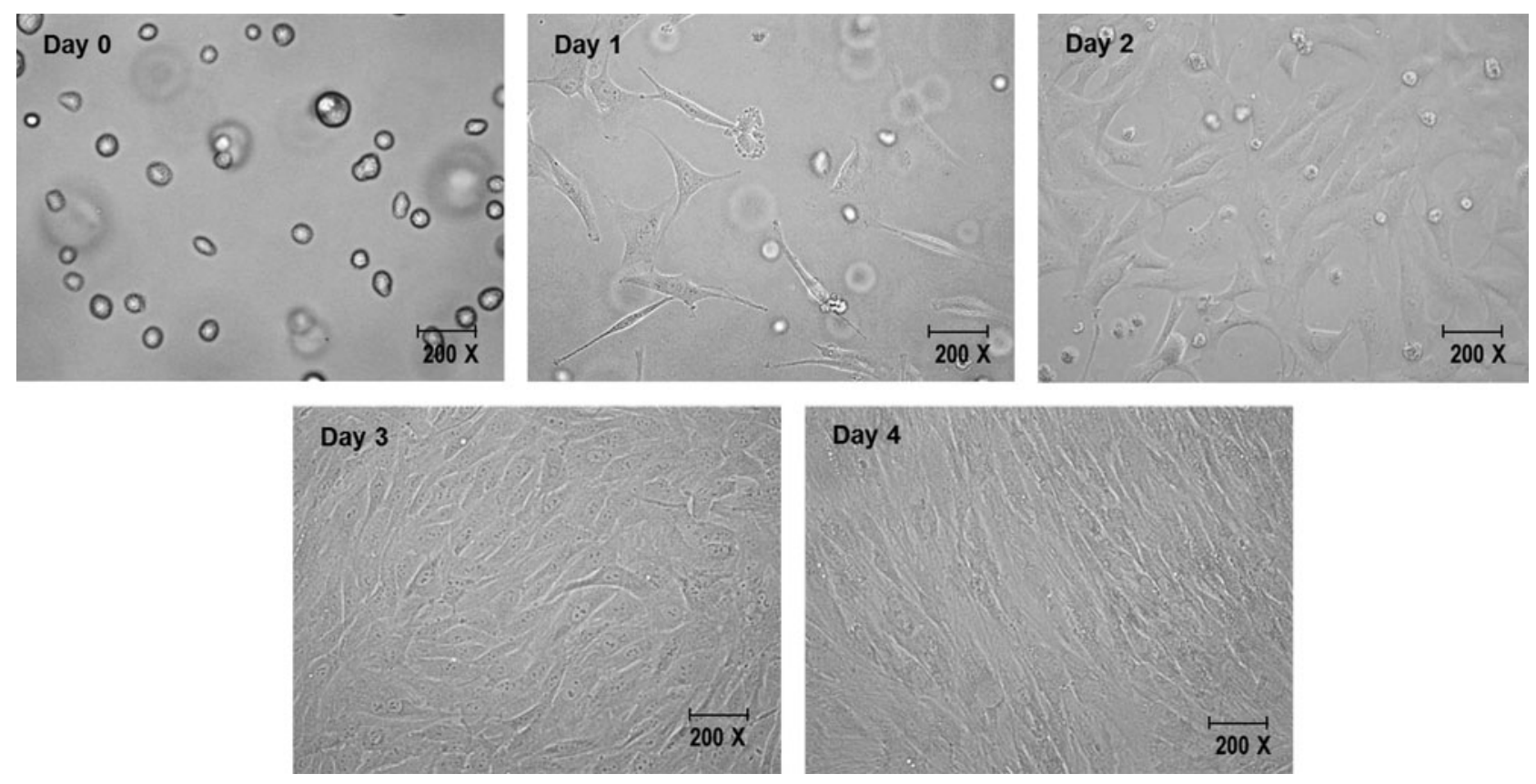

FIG. 2. Morphology of cultured skin-derived fibroblasts following aerosolization. The cells are actively proliferating and become confluent after 4 days of culture.

\section{Discussion}

Intratracheal cell delivery using the MicroSprayer Aerosolizer is a novel technique for delivering medium containing transplant cells directly into the lungs. This method will have a great impact on the application of cell-based therapy, as it offers advantages over other types of cell delivery.

Vacuolation is the formation of large vacuoles inside the cytoplasm as a cellular response to maintain survival and functional status under stressful conditions. ${ }^{(13)}$ Use of the MicroSprayer Aerosolizer to transform the medium containing cells of interest is stressful to the cells due to the pressure required to transform liquid into aerosol form. However, microscopic observation of cell morphology following aerosolization showed that neither surviving skinderived fibroblasts nor HeLa cells exhibited vacuolation. In the skin-derived fibroblast culture, the spindle-shaped fibroblasts formed after $24 \mathrm{hr}$ in the medium. The cells were
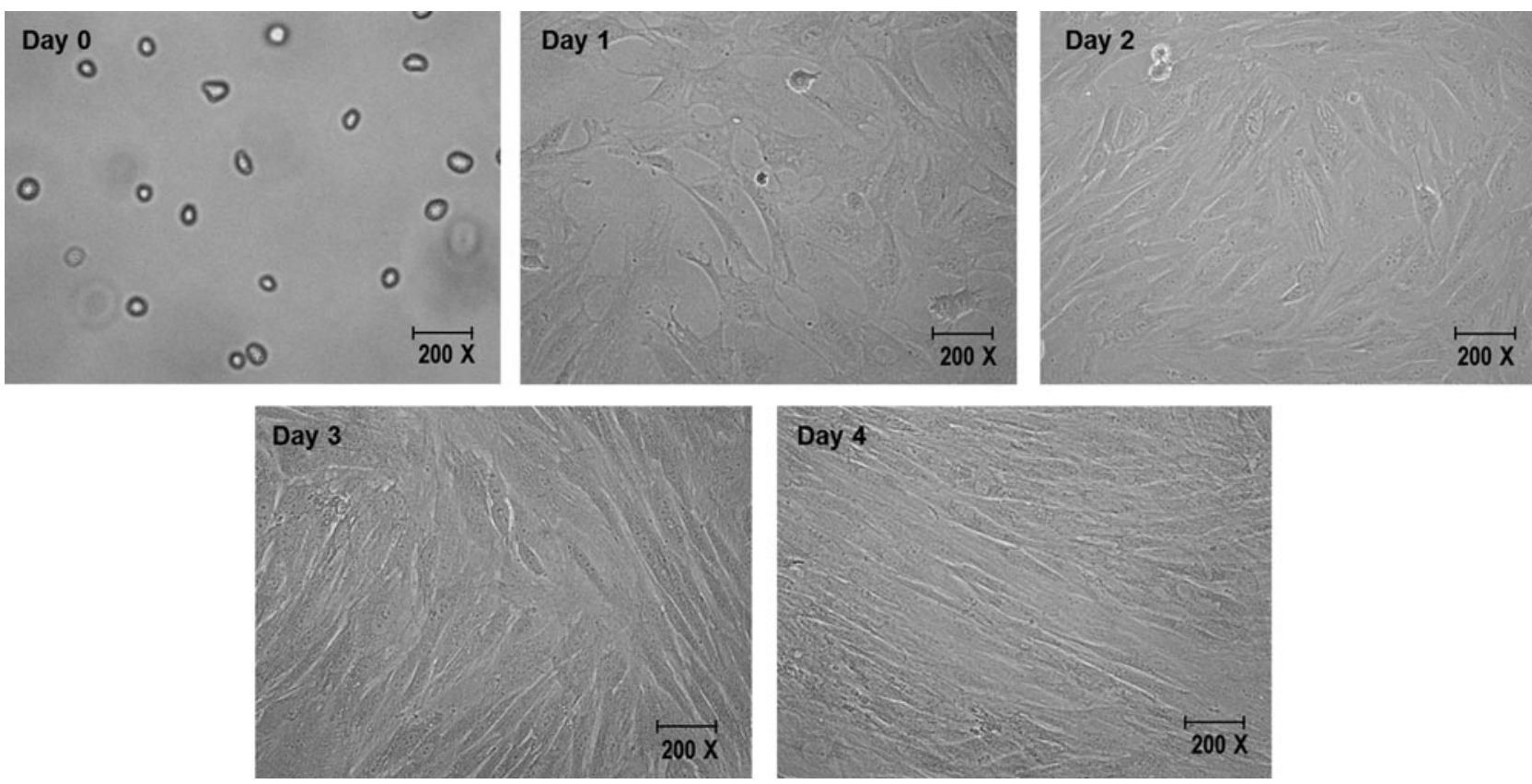

FIG. 3. Morphology of nonaerosolized skin-derived fibroblasts. Like aerosolized skin-derived fibroblast cells, nonaerosolized skin-derived fibroblast cells actively proliferate and become confluent after 4 days of culture. 

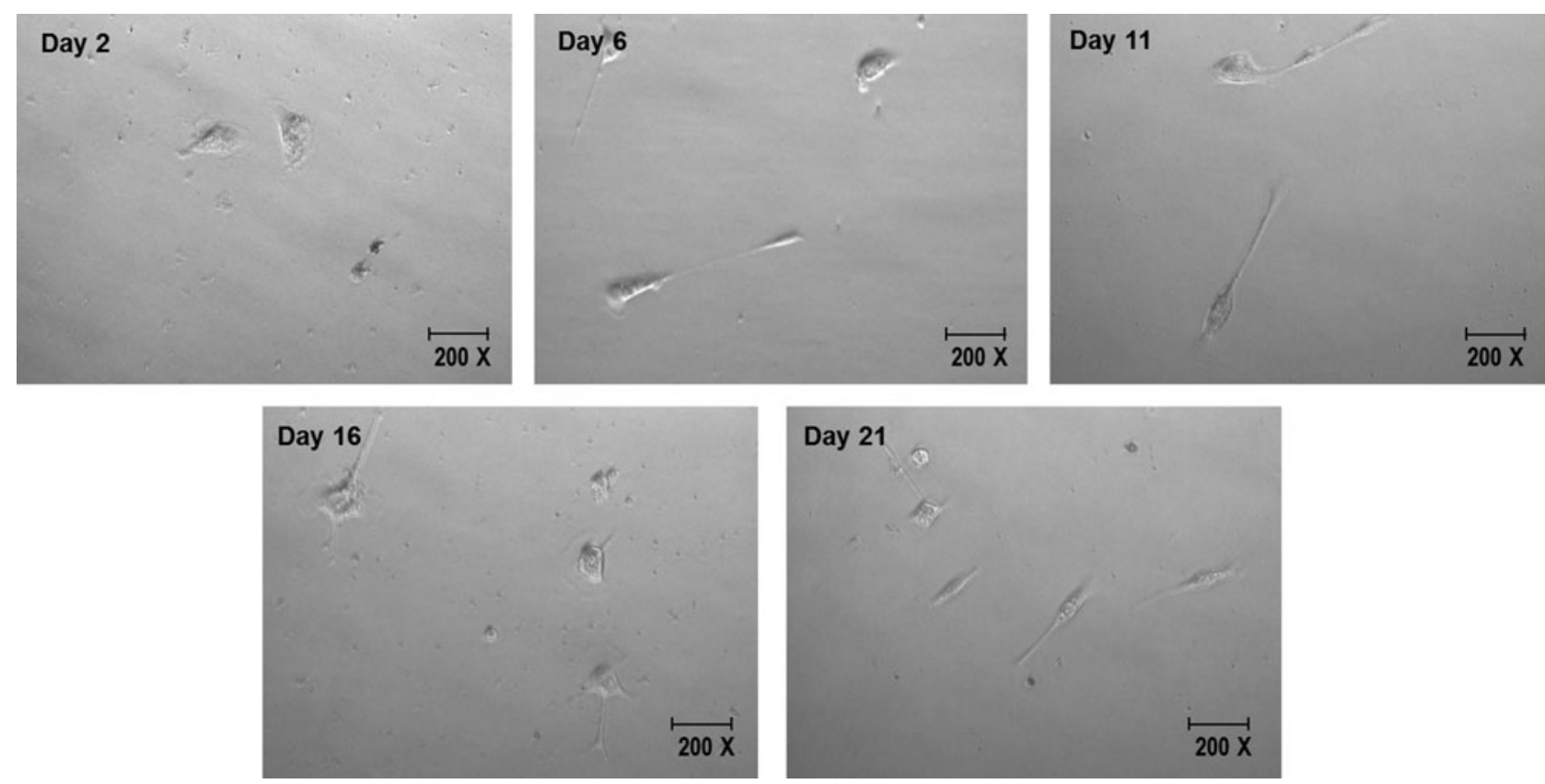

FIG. 4. Morphology of cultured HeLa cells following aerosolization. The proliferation of HeLa cells was very low even though the culture was maintained for 21 days; only a small number of cells survived following aerosolization.

actively proliferating and became confluent after 4 days. However, the medium containing HeLa cells contained excessive amounts of dead cells even after 21 days of culture.

The size of the MicroSprayer's aerosolizer is $25-30 \mu \mathrm{m}$. We hypothesise that skin-derived fibroblast cells had a higher survival rate than HeLa cells following aerosolization because fibroblast cells (10-15 $\mu \mathrm{m}$ in diameter) are smaller than the aerosolizer, ${ }^{(14)}$ and thus they can easily pass through the tip of the apparatus. In contrast, a typical HeLa cell is 10$30 \mu \mathrm{m}$ in width and $40-70 \mu \mathrm{m}$ in length. ${ }^{(15)}$ Therefore, the majority of HeLa cells were trapped inside the aerosolizer, and the pressure applied to the syringe likely caused the cell membrane to lyse, resulting in a lot of dead cell debris following aerosolization.

In vivo studies of delivering cells into the lungs via intratracheal, ${ }^{(1)}$ intrapulmonary, ${ }^{(4)}$ or intravenous ${ }^{(16)}$ routes resulted in a low survival rate of delivered cells. Thus, engraftment of exogenous stem cells into the lungs remains controversial. ${ }^{(17)}$ Leblond et al. used stem cells as a vehicle to deliver a therapeutic gene to treat a genetic airway disease; via the intratracheal route of delivery in their murine model of airway injury, only $0.43-5.5 \%$ of stem cells were successfully engrafted in the injured lung at $24 \mathrm{hr}$ following delivery. ${ }^{(1)}$ Gupta et al. used the intrapulmonary cell delivery route to administer mesenchymal stem cells (MSCs) into mice with an endotoxin-induced acute lung injury; even though the result showed a significant histological improvement in the severity of lung injury, less than $5 \%$ of MSCs engrafted after $48 \mathrm{hr}$ of administration. ${ }^{(4)}$ In a study using the intravenous route of delivery of MSCs into a bleomycin-induced lung injury in mice, the engraftment levels of the administered cells were low. ${ }^{(16)}$ One of disadvantages of using the intrapulmonary or intravenous route of delivery is that the administered cells are unable to localize directly to the specific organ of interest, as the mi- gration process is away from the targeted organ and thus might dilute the number of transplanted cells. This occurs because any inflammatory responses associated with injury in a particular organ will influence the migration of transplanted cells to participate in the repair process, which means that the number of cells that reach the target organ becomes less. Delivering the transplant cells directly to the target organ using aerosol delivery will help to reduce their unnecessary involvement in organ repair.

The high survival rate of skin-derived fibroblasts following aerosolization makes them great candidates as target cells for aerosolized delivery to treat lung injury. Fibroblasts maintain the structural integrity of connective tissues by continuously secreting the precursor extracellular matrix. ${ }^{(18)}$ When a tissue is injured, nearby fibroblasts are activated and differentiate into myofibroblasts, which participate in wound healing through migration, proliferation, contraction, and production of large amounts of extracellular matrix. ${ }^{(18)}$ Kobayashi et al. also found that fibroblasts are capable of activating epithelial cell proliferation and accelerate the growth of airway epithelial cells that lead to reconstruction of a pseudostratified epithelium. ${ }^{(19)}$

\section{Conclusion}

The aerosolized cell delivery technique has potential as an effective delivery route for cell-based therapy to treat patients with lung-related diseases, especially using fibroblasts as target cells. This method might offer significant preclinical and clinical advantages compared with other types of delivery, as indicated by the high survival rate of cells following aerosolization in vitro. This study provides the first evidence that cells can be aerosolized without the risk of low cell survivability and stress. An in vivo approach using aerosolized cell-based therapy is ongoing in our laboratory, 
and we hope it will lead to an innovative therapeutic treatment with high cell survival and engraftment into the lung.

\section{Acknowledgments}

This study was supported by grants from the Universiti Sains Malaysia (USM) Short Term Grant Scheme (304/ CIPPT/61312001) and the E-Science Fund Research Grant Scheme under the Ministry of Science, Technology and Innovation (MOSTI) (305/CIPPT/613224).

\section{Author Disclosure Statement}

The authors report no conflicts of interest. The authors alone are responsible for the content and writing of the article.

\section{References}

1. Leblond AL, Naud P, Forest V, Gourden C, Sagan C, Romefort B, Mathieu E, Delorme B, Collin C, Pagès JC., Sensebé L, Pitard B, and Lemarchand P: Developing cell therapy techniques for respiratory disease: intratracheal delivery of genetically engineered stem cells in a murine model of airway injury. Hum Gene Ther. 2009;20:1329-1343.

2. Bragonzi A, Dina G, and Villa A: Biodistribution and transgene expression with non-viral cationic vector/DNA complexes in the lung. Gene Ther. 2000;7:1753-1760.

3. Fischer UM, Harting MT, Jimenez F, Monzon-Posadas MO, Xue H, Savitz SI, Laine GA, and Cox CS Jr: Pulmonary passage is a major obstacle for intravenous stem cell delivery: the pulmonary first-pass effect. Stem Cells Dev. 2009; 18:683-692.

4. Gupta N, Su X, Popov B, Lee JW, Serikov V, and Matthay MA: Intrapulmonary delivery of bone marrow-derived mesenchymal stem cells improves survival and attenuates endotoxin-induced acute lung injury in mice. J Immunol. 2007;179:1855-1863.

5. Goula D, Becker N, and Lemkine GF: Rapid crossing of the pulmonary endothelial barrier by polyethylenimine/DNA complexes. Gene Ther. 2000;7:499-504.

6. Kichler A, Chillon M, and Leborgne C: Intranasal gene delivery with a polyethylenimine-PEG conjugate. J Control Release. 2002;81:379-388.

7. Crisanti MC, Koutzaki SH, Mondrinos MJ, Lelkes PI, and Finck CM: Novel methods for delivery of cell-based therapies. J Surg Res. 2008;146:3-10.

8. Xisto DG, Abreu SC, Antunes MA, Crossetti J, Capelozzi VL, Morales MM, and Rocco PRM: Intratracheal versus intravenous bone marrow mononuclear cell therapy in experimental chronic allergic asthma: which is the best administration route? Am J Respir Crit Care Med. 2011;183:A3588.

9. Wong AP, Dutly AE, Sacher A, Lee H, Hwang DM, Liu M, Keshavjee S, Hu J, and Waddell TK: Targeted cell replacement with bone marrow cells for airway epithelial regeneration. Am J Physiol Lung Cell Mol Physiol. 2007;293: L740-L752.

10. Chiang PC, Alsup W, Lai Y, Hu Y, Heyde BR, and Tung D: Evaluation of aerosol delivery of nanosuspension for pre- clinical pulmonary drug delivery. Nanoscale Res Lett. 2009; 4:254-261.

11. Lai Y, Chiang PC, Blom JD, Li N, Shevlin K, Brayman TG, $\mathrm{Hu}$ Y, Selbo JG, and Hu LG: Comparison of in vitro nanoparticles uptake in various cell lines and in vivo pulmonary cellular transport in intratracheally dosed rat model. Nanoscale Res Lett. 2009;3:321-329.

12. Lin H, Li H, Cho H, Bian S, Roh H, Lee M, Kim J, Chung S, Shim C, and Kim D: Air-liquid interface (ALI) culture of human bronchial epithelial cell monolayers as an in vitro model for airway drug transport studies. J Pharm Sci. 2007; 96:341-350.

13. Henics T, and Wheatley DN: Cytoplasmic vacuolation, adaptation and cell death: a view on new perspectives and features. Biol Cell. 1999;91:485-498.

14. Freitas AR Jr: Nanomedicine, Volume I: Basic Capabilities. Landes Bioscience, Georgetown, TX; 1999.

15. Yehia HN, Draper RK, Mikoryak C, Walker EK, Bajaj P, Musselman IH, Daigrepont MC, Dieckmann GR, and Pantano P: Single-walled carbon nanotube interactions with HeLa cells. J Nanobiotechnol. 2007;5:8.

16. Ortiz LA , Gambelli F, McBride C, Gaupp D, Baddoo M, Kaminski N, and Phinney DG: Mesenchymal stem cell engraftment in lung is enhanced in response to bleomycin exposure and ameliorates its fibrotic effects. Proc Natl Acad Sci USA. 2003;100:8407-8411.

17. Loebinger MR, Sage EK, and Janes SM: Mesenchymal stem cells as vectors for lung disease. Proc Am Thorac Soc. 2008; 5:711-716.

18. Haniffa MA, Collin MP, Buckley CD, and Dazzi F: Mesenchymal stem cells: the fibroblasts' new clothes? Haematologica. 2009;94:258-263.

19. Kobayashi K, Nomoto Y, Suzuki T, Tada Y, Miyake M, Hazama A, Kanemaru S, Nakamura T, and Omori K: Effect of fibroblasts on tracheal epithelial regeneration in vitro. Tissue Eng. 2006;12:2619-2628.

Received on October 10, 2012 in final form, January 20, 2013

Reviewed by: Peter Anderson Hussein Foda

Address correspondence to: Dr. Badrul Hisham Yahaya, Senior Lecturer Cluster for Regenerative Medicine Advanced Medical $\mathcal{E}$ Dental Institute (AMDI) Universiti Sains Malaysia

No 84 Level 1 (Lot 45-2) Persiaran Seksyen 4/9 Bandar Putra Bertam 13200 Kepala Batas Penang Malaysia E-mail: badrul@amdi.usm.edu.my 